\title{
Proyectos y experiencias \\ El Ecomuseo del Río Caicena en Almedinilla (Córdoba). \\ Desarrollo rural desde el patrimonio histórico-natural y la participación ciudadana
}

El Ecomuseo del Río Caicena es un proyecto municipal de desarrollo territorial, entendido de manera equilibrada, sostenible y en sintonía con el patrimonio histórico y natural del término municipal, que sirve de referente para otras actuaciones territoriales del Ayuntamiento.

Tanto los que elaboramos el proyecto y trabajamos en él, cuanto el propio Ayuntamiento que lo hizo suyo e impulsa, así como las asociaciones que participan en su desarrollo, compartimos la intención de convertir el proyecto de ecomuseo en un instrumento de participación y reflexión sobre el presente, que frene y denuncie los efectos de una economía y sociedad que sólo busca el beneficio monetario (por encima del patrimonio histórico, del entorno natural, de los valores comunitarios y de la propia salud), promoviendo la precariedad laboral, el individualismo asocial, y relegando al mundo rural a un papel cada vez más marginal y dependiente.

Esta intención que nos anima no está exenta de tensiones, contradicciones, desencuentros, pérdidas y algunos logros y alegrías, pero creemos que está sirviendo para generar un debate abierto y continuo que desde el conocimiento del territorio y

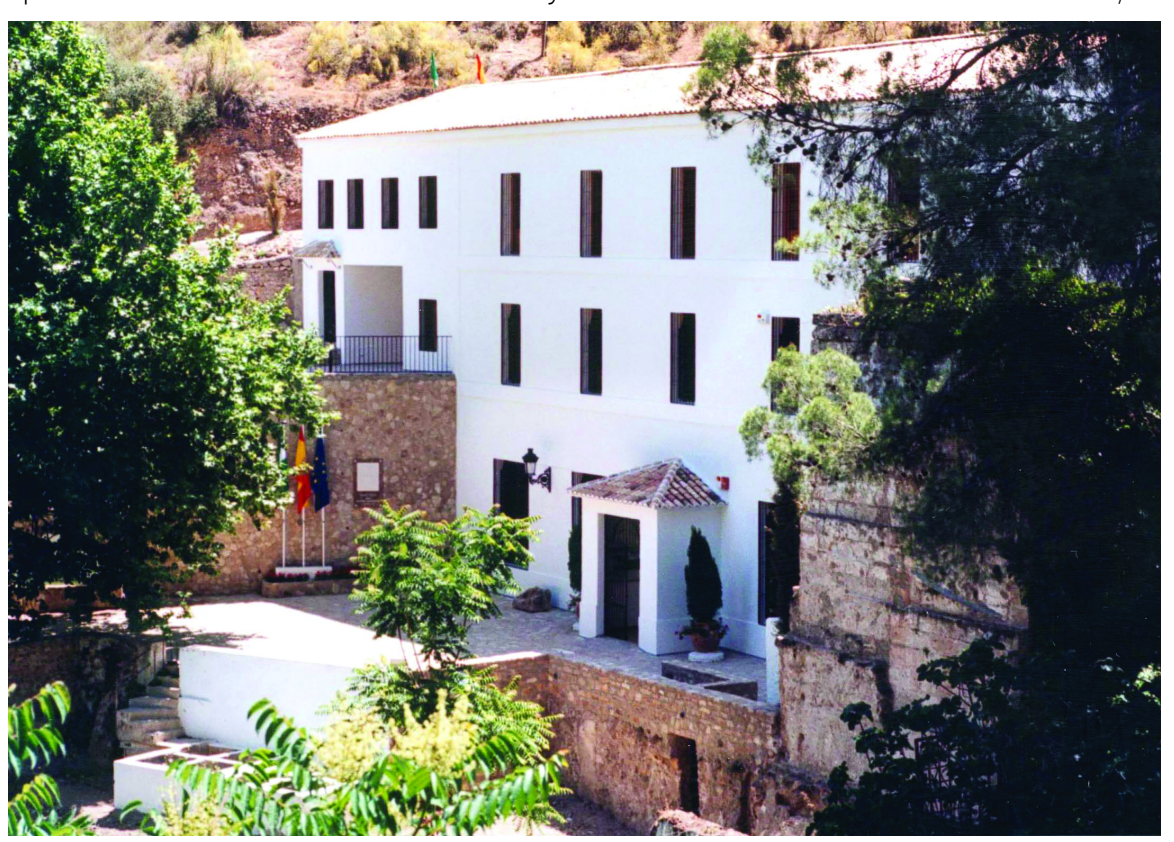

Fachada del Museo Histórico su devenir histórico (expresado en su patrimonio histórico y natural) nos ayude a entender mejor nuestro presente y encarar con mayor solidez el futuro.

Para nosotros este es el mejor modelo de desarrollo, es decir, el que parte de la dinamización social y cultural, a través de la reflexión crítica y la participación en el análisis de los problemas y en la búsqueda de soluciones. De hecho, la cultura y el patrimonio (lejos de visiones academicistas y elitistas) han sido siempre referente de Lo Público, han favorecido la formación crítica, y son un marco idóneo para promover la participación ciudadana y el establecimiento de cauces comunitarios.

Desde el punto de vista económico no cabe duda que en la Subbética Cordobesa (donde se inserta este pequeño y blanco municipio de 2.500 habitantes) el motor más importante lo constituye el olivar (aunque dentro de una economía poco diversificada, con poco aprovechamiento integral, con escasa comercialización directa del aceite, con problemas medioambientales asociados, y con gran dependencia de la P.A.C. de la Unión Europea y de las politicas estatales). Sin embargo, otros recursos entre los que cabría citar los derivados de la huerta tradicional, la ganadería caprina, o los patrimoniales-turísticos se pueden convertir en motores complementarios que favorezcan la necesaria diversificación económica.

Desde el Ecomuseo del Río Caicena, a partir de sus diferentes núcleos museísticos, de sus actividades didácticas, de la organización de cursos y seminarios, de proyectos de investigación y de desarrollo, incidimos en analizar los procesos de dependencias del campesinado y del mundo rural a lo largo de la Historia, y en la importancia de promover la diversidad y la diversificación en todos los aspectos de la vida: en los económicos, en los culturales, y en los medioambientales.

Si desde el Ecomuseo se promueve un núcleo museístico nuevo, una actuación de mejora del entorno natural, la recuperación de un camino ganadero, una nueva actividad didáctica... lo primero que se busca es esa diversificación de recursos y a través de ello conseguir mejorar la calidad de vida del habitante de la localidad y de la comarca (el tener un entorno cuidado, un camino recuperado, un museo, una calle empedrada... no se debe hacer pensando en el turista sino en los vecinos y vecinas que vivimos en la localidad). Si además se atrae con ello a un turismo respetuoso, que valora e integra en su experiencia lo que ve, y que ayuda a mantener infraestructuras y puestos de trabajo, generando un movimiento económico (bares, restaurantes, alojamientos rurales...) y dando vida y alegría a calles y plazas, mejor que mejor.

Si no se consigue ningún ingreso económico de las actividades turístico-culturales tal vez se debería pensar en cambiar el planteamiento, la visión y la gestión de esos recursos (más participada, flexible y ágil por ejemplo), pero no por ello eliminar inversiones o infraestructuras necesarias para potenciar esos bienes públicos (que sin menoscabo de las necesarias inversiones privadas no deberian dejar además de ser inversiones fundamentalmente públicas): Ios colegios, institutos y universidades -por no mencionar hospitales y centros de salud- tampoco generan ingresos y 


\section{$102-103$ \\ Debate e Investigación \\ Proyectos y experiencias \\ PH42 - Febrero 2003}

no por ello se deben eliminar (cuestiones de perogrullo que en los tiempos que vivimos hasta parecen cuestionarse).

En nuestro caso, a raíz de la puesta en funcionamiento del proyecto de ecomuseo, se ha creado un movimiento sociocultural y también económico (ver ficha) interesante. La infraestructura del Ecomuseo se costeó con dinero público y actualmente se mantiene con los ingresos, al tiempo que se han generado puestos de trabajo directos e indirectos. Por otro lado, a través del Patronato Municipal Hypnos (en el que participa Ayuntamiento y Diputación de Córdoba) se van generando nuevos recursos, aunque con la voluntad de no sobredimensionar capacidades e instalaciones.

En cualquier caso, para valorar con cierta perspectiva proyectos como el que nos ocupa deberian pasar otros 12 años, y comprobar el grado de participación ciudadana final (en Almedinilla se ha pasado de la indiferencia hacia el patrimonio local a la valoración y el respeto del mismo, pero falta que la población se "apropie" de su patrimonio participando aún más en su gestión); comprobar si los cambios políticos no afectan a la visión y objetivos del Ecomuseo; si la coordinación de las administraciones mejora (por ejemplo entre ayuntamientos y consejerias, entre Consejería de Cultura y Agricultura, en relación a los Fondos Europeos, o entre Cultura y Turismo...), o si los ayuntamientos, y los ayuntamientos pequeños de núcleos rurales, incrementan su autonomía de gestión y fuentes de financiación.

Ignacio Muñiz Jaén

Director del Ecomuseo del Río Caicena Museo Histórico de Almedinilla
Momento de las cenas romanas

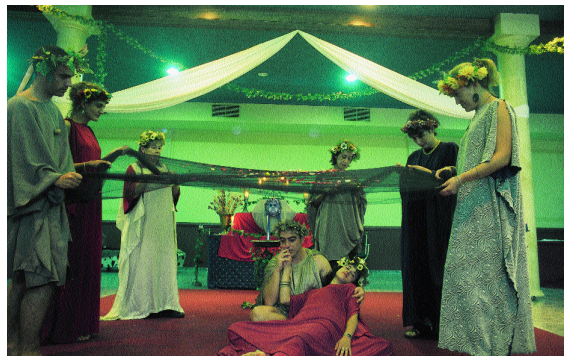

\section{Almedinilla}

Ubicación:

Inversiones:

Subbética Cordobesa.

$N^{\circ}$ de habitantes:

2.500 .

\section{Año de inicio:}

1994-97:

elaboración del proyecto, trabajos de concienciación y dinamización, proyectos de restauración y rehabilitación...

1999:

funcionan los núcleos museisticos principales, comienza la promoción y comercialización.

\section{Promotores:}

Ayuntamiento de Almedinilla, diferentes asociaciones.

Colaboradores:

Diputación de Córdoba, Consejería de Cultura, Consejería de Turismo, CajaSur.

\section{Núcleos museisticos:}

Museo Histórico, Aula del Caicena, Recorrido de Educación Ambiental, Centro de Recepción y de Exposiciones Temporales, Sala de los Molinos y los Cereales, yacimiento ibérico de El Cerro de la Cruz y villa romana de El Ruedo, Sala de Talleres y Conferencias,

Biblioteca y alojamiento para investigadores, Taller de Restauración y Almacén, Rutas Senderistas (Ruta de los Molinos, Ruta de Albayate, Ruta de la Bética Romana, Ruta Histórico-Arqueológica de la Subbética. Ruta Senderista GR 7).

\section{Actividades:}

Investigación (proyecto "OIKOS"), catalogación y restauración, publicación de monografia, elaboración de proyectos de desarrollo, organización de congresos y jornadas, talleres para escolares (arqueología, etnografía y medioambiente), paquetes turisticos (entre ellos el denominado "Un Día en la Bética Romana", con comidas romanas y teatralizaciones).
Fijas y anuales (a trav és del Ayuntamiento de Almedinilla y el Patronato Municipal Hypnos): 36.000 euros.

Puntuales (a cargo de diversas consejerías, Diputación de Córdoba, INEM y fondos europeos desde 1994-2002): 843.373 euros (aproximadamente).

Puestos de trabajo directos:

2 a tiempo completo; $2-3$ a tiempo parcial; cooperativa (7-8 personas); comidas romanas (4-5 personas).

Puestos de trabajo indirectos:

2 restaurantes, 10 alojamientos rurales y 1 hotel rural (antes del proyecto no existía ninguno). Una pensión, una fábrica de embutidos, dos almazaras de aceite y dos bares también se benefician directamente de los "paquetes turísticos".

$N^{0}$ de visitas:

En el 2001: 10.209 personas.

Ingresos brutos:

Entradas, talleres, paquetes turisticos, ventas: 52.048 euros (año 2001).

Taller con pasacalles

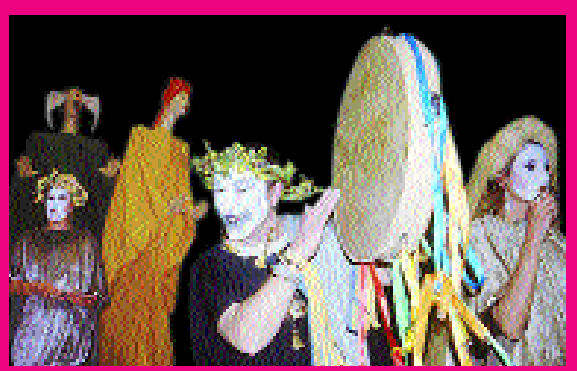

